BUZZO, A.M.R. e MARTINEZ, A.C. Influência da diferença esperada na progênie no preço da dose do sêmen de touros da raça Nelore. PUBVET, Londrina, V. 8, N. 14, Ed. 263, Art. 1747, Julho, 2014.

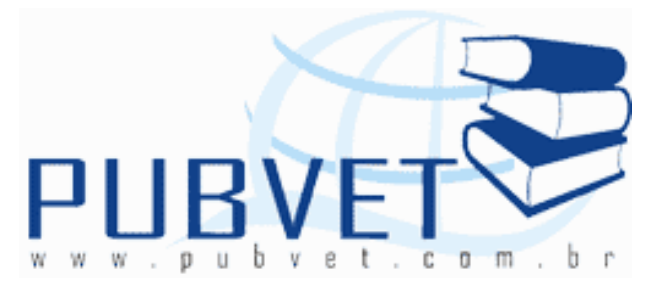

PUBVET, Publicações em Medicina Veterinária e Zootecnia.

\title{
Influência da diferença esperada na progênie no preço da dose do sêmen de touros da raça Nelore
}

\author{
Álida Mariana dos Reis Buzzo e Antonio Campanha Martinez*
}

Universidade Estadual de Maringá - Campus Umuarama - Departamento de Medicina Veterinária. Estrada da Paca s/n. Caixa Postal 65. CEP 87501-970. *acmartinez@uem.br

\section{Resumo}

O objetivo do trabalho foi avaliar o valor comercial das doses de sêmen e correlacionar com algumas Diferenças Esperadas na Progênie (DEPs) e com as premiações obtidas em exposições credenciadas pela Associação Nacional dos Criadores de Nelore do Brasil (ANCB), para verificar o que influencia no preço final da dose de sêmen. Os dados foram obtidos junto à ANCB e no Sumário 2008: Avaliação Genética de Touros e Matrizes da Raça Nelore do Programa de Melhoramento Genético da Raça Nelore (PMGRN-USP). Os dados foram tratados estatisticamente com auxílio do PROC COR do programa SAS V8.0. Como resultado, somente as provas de progênie, do primeiro ao terceiro lugar mostraram correlação no preço do sêmen, com 60,6\%, 60,2\% e 56,5\% respectivamente. Quanto às DEPs, a característica peso ao nascimento foi a que mais se destacou entre as outras, com uma influência de $17,6 \%$ sobre o preço da dose. As características genéticas, que são as de maior importância quando se quer melhorar um plantel, ainda não estão sendo determinantes no 
BUZZO, A.M.R. e MARTINEZ, A.C. Influência da diferença esperada na progênie no preço da dose do sêmen de touros da raça Nelore. PUBVET, Londrina, V. 8, N. 14, Ed. 263, Art. 1747, Julho, 2014.

preço da dose de sêmen comercial e com esta análise pode-se verificar que as características fenotípicas dos touros tem influenciado mais que as características genéticas herdáveis.

Palavras-chave: Herdabilidade. Correlação. Progênie.

\title{
Influence of the expected progeny difference in price of dose of Nelore semen
}

\begin{abstract}
The aim of this study was to evaluate the commercial price of bull's semen and estimate it's correlation with genetic characteristics (from the Summary of Program of Genetic Improvement of the Nelore Breed - PMGRN) and with the prizes from Competitions of National Association of Brazil's Nelore Breeders (ANCB), and verify what influences the final price of bull semen. Data were collected from both ANCB and PMGRN's Summary 2008. The PROC COR's SAS V8.0 program was used. Results show that, only the bulls whose calf had won prizes, from the first to the third place, had correlation with the bull's semen, with $60,6 \%, 60,2 \%$ and $56,5 \%$, respectively. About the heritability characteristics, the only one which had correlation with semen price was birth of weight, with an influence of $17,6 \%$ on the bull's semen price. The most important genetic characteristics when aiming at improving cattle's genotype in a farm have not been used to determine the price of each dose of commercial semen. Therefore, the present investigation showed that the cattle's phenotipe has influenced more than inherited characteristics.
\end{abstract}

Keywords: Correlation; Heritability; Progenie

\section{INTRODUÇÃO}

O Brasil é um país de proporções continentais que possui diferentes sistemas de exploração de bovinos, com grande número de produtores. A criação varia de acordo com as condições climáticas, econômicas e de recursos naturais relacionados à produção animal encontradas em cada região 
BUZZO, A.M.R. e MARTINEZ, A.C. Influência da diferença esperada na progênie no preço da dose do sêmen de touros da raça Nelore. PUBVET, Londrina, V. 8, N. 14, Ed. 263, Art. 1747, Julho, 2014.

(FREITAS, et al., 2003; LOPES et al., 2008). Apesar de possuir um rebanho numeroso, o país possui uma baixa taxa de abate, quando comparado com países de pecuária mais desenvolvida, os quais apresentam índices acima de $30 \%$ enquanto no Brasil é de $23 \%$. Todavia o rebanho numeroso proporciona ao Brasil o posto de terceiro maior produtor mundial de carne bovina, somente atrás dos EUA e da China (ANUALPEC, 2012).

A pecuária de corte brasileira desenvolveu-se devido à expansão da fronteira agrícola, incorporando ao sistema extensivo de produção novas áreas em regiões desprovidas de infra-estrutura e pela utilização de terras esgotadas pela produção de grãos. A atividade contribuiu desde os tempos coloniais para a ocupação do território brasileiro, função essa que ainda ocorre em algumas áreas de novas fronteiras agrícolas (IEL, CNA e SEBRAE, 2000) nas regiões Centro-Oeste e Norte do país.

A atividade passa por uma fase de crescimento e modernização. Os produtores rurais estão tendo acesso às informações e estratégias seletivas que melhoram seus rebanhos nas características de produção, reprodução e crescimento, e conseqüentemente aumentam a eficiência reprodutiva das fazendas (GUNSKI et al., 2001b; GRESSLER et al., 2005). Essas mudanças tecnológicas ocorrem principalmente nas regiões Centro-Oeste, Sul e Sudeste.

O crescimento aconteceu principalmente em virtude da exportação, sendo que em 2003 e 2004 o país esteve em primeiro lugar como exportador (CNA, 2006). Países como Rússia e mercados Europeus (Países Baixos, Alemanha, Reino Unido, e Itália) são os principais destinos, tanto de carne in natura quanto industrializada, e os mercados da América do Norte (Estados Unidos e Canadá) são o segundo maior exportador: exportam somente carne industrializada.

Segundo o estudo realizado pelo IEL, CNA e SEBRAE em 2000, o rebanho brasileiro é constituído de aproximadamente $85 \%$ de zebuínos. Devido à capacidade de adaptação ao nosso clima tropical com altas temperaturas, à resistência a endo e ectoparasitos e falhas no manejo alimentar, que o Zebu tem se mostrado o biotipo mais adequado para a exploração agropecuária no 
BUZZO, A.M.R. e MARTINEZ, A.C. Influência da diferença esperada na progênie no preço da dose do sêmen de touros da raça Nelore. PUBVET, Londrina, V. 8, N. 14, Ed. 263, Art. 1747, Julho, 2014.

Brasil, onde a raça Nelore tem se destacado grandemente entre os criadores (ELER, et al., 1995; JOSAHKIAN, 2000; PINEDA, 2000; GUNSKI et al., 2001a) por possuir grande rusticidade e fertilidade.

Segundo Griffiths, (2001) é fácil determinar se uma variação genética influencia a variação fenotípica, pois, quando genes estão envolvidos os parentes biológicos devem se assemelhar uns aos outros mais que os indivíduos não aparentados, sendo esta uma correlação genética positiva entre os genitores e a prole ou entre irmãos. A habilidade para mudar fenótipos por cruzamentos seletivos indica que a variação tem uma base genética (SNUSTAD, 2001). Durante a maior parte da história da genética a semelhança fenotípica foi o único método disponível para se estabelecer herdabilidade de uma característica (GRIFFITHS, 2001), porém, hoje em dia com os estudos mais aprofundados sobre segregação de genes e sequenciamento de genoma, que nos tornou possível entender como algumas características são herdadas e expressadas pela progênie através da herdabilidade, que é o grau no qual uma determinada característica é controlada por herança (SNUSTAD, 2001)

Em 1988 foi criado o Programa de Melhoramento Genético da Raça Nelore da Universidade de São Paulo (PMGRN-USP) que atualmente é o programa de melhoramento oficial da Associação Nacional dos Criadores de Nelore do Brasil (ANCB). O programa faz a avaliação genética de touros e vacas avaliando as características genéticas desses animais e de suas progênies, buscando características desejáveis para melhorar o rebanho brasileiro. Características reprodutivas e de precocidade de crescimento têm sido consideradas como prioritárias na seleção em bovinos de corte (GRESSLER et al., 2005; PEREIRA et al., 2005; BOLIGON et al., 2007; BOLIGON et al., 2008a; BOLIGON et al., 2008b; FARIA et al., 2008; SANTANA JR et al., 2013) onde por meio delas, é possível aumentar a eficiência para ganho de peso, reduzir o tempo de permanência dos animais a pasto, minimizando assim o tempo de abate (LIRA et al., 2008). Essas informações são dadas em números e chamadas de DEPs (Diferenças Esperadas na Progênie), que medem a habilidade de transmissão genética de um animal 
BUZZO, A.M.R. e MARTINEZ, A.C. Influência da diferença esperada na progênie no preço da dose do sêmen de touros da raça Nelore. PUBVET, Londrina, V. 8, N. 14, Ed. 263, Art. 1747, Julho, 2014.

avaliado como progenitor, e demonstra o quanto se espera que os filhos daquele touro sejam superiores ao restante da população (PANETO et al., 2000; LÔBO,et al., 2008), o cálculo das DEPs possibilita uma avaliação do desempenho de um plantel, podendo-se avaliar muitas características econômicas (SHIOTSUKI, et al., 2004) sendo que as DEPs são expressas na unidade da característica: em quilos para peso, em centímetros para perímetro escrotal, em meses para idade ao primeiro parto, podendo ter sinal positivo ou negativo.

Essa ferramenta de seleção já participa do dia-a-dia do criador e tem agregado valor econômico na comercialização de animais nas fazendas e leilões (PANETO et al., 2000; LÔBO et al., 2003).

A base genética do PMGRN teve como base as DEPs dos animais fundadores do programa e foi de valor zero. Esses animais eram sem pedigree de um ou ambos os pais e o valor não foi a media de todos os animais analisados (LÔBO et al., 2003).

Na genética são usados os termos genótipo e fenótipo para diferenciar a expressão visível das características da constituição genética real (GARDNER,2000). O genótipo é então definido como a constituição genética de um organismo e o fenótipo são as características observáveis desse organismo (SNUSTAD, 2001), sendo a expressão do genótipo somada à interação com o ambiente.

O produtor ao escolher animais para o acasalamento em sua propriedade deve levar em conta as DEPs que satisfaçam os seus objetivos e os critérios da sua seleção (LÔBO et al., 2003). O aumento da produtividade pode ser obtido a partir da identificação e multiplicação dos melhores genótipos e da adequação das condições ambientais relacionadas ao processo produtivo (ZAMPAR, 2007). Pode-se escolher um touro que traga ganhos genéticos ao seu rebanho e maior lucratividade num menor espaço de tempo, escolhendo DEPs para que o bezerro seja desmamado mais cedo e chegue à idade adulta mais pesado e tenha um maior potencial para reprodução.

Carter et al. (1971) analisaram o efeito da eficiência da seleção de touros 
BUZZO, A.M.R. e MARTINEZ, A.C. Influência da diferença esperada na progênie no preço da dose do sêmen de touros da raça Nelore. PUBVET, Londrina, V. 8, N. 14, Ed. 263, Art. 1747, Julho, 2014.

com base na correlação do PD com o peso final e concluíram que a seleção, baseada no peso à desmama ou ao ano, pode resultar em bom ganho genético. Já Eler et al 1996 e Garneiro et al., 2002 sugeriram o PD como o melhor critério de seleção, do ponto de vista prático e econômico, apesar da influência dos efeitos maternos. Vale ressaltar que a utilização do peso como critério de seleção é fundamental, uma vez que os produtores são remunerados pelo peso vivo dos animais ao abate (BOLIGON et al., 2008a).

Este trabalho teve como objetivo avaliar o valor comercial das doses de sêmen, correlacionando com as principais DEPs, fornecidas pelo Sumário do PMGRN-USP, com as premiações obtidas em exposições credenciadas pela Associação Nacional dos Criadores de Nelore do Brasil (ANCB).

\section{MATERIAL E MÉTODOS}

Foi utilizado como fonte das DEP's dos touros o Sumário do PMGRN-USP 14ª edição (LÔBO et al., 2008), e selecionados 117 touros Nelore, premiados ou não, produtores de sêmen em Centrais de Inseminação Artificial.

O critério de escolha desses touros foi estar presente no Sumário (LÔBO et al., 2008) e pertencer ao quadro de doadores de sêmen de Centrais de Inseminação Artificial. Nestas Centrais foi obtido o valor comercial das doses dos referidos touros.

As premiações dos reprodutores foram obtidas junto à Associação Nacional dos Criadores de Nelore do Brasil (ANCB).

As DEPs avaliadas foram: peso ao nascer ( $P N)$, idade ao primeiro parto (IPP), período de gestação (PG), peso adulto (PA), produtividade acumulada (PAC), peso aos 120 dias (P120), peso aos 365 dias (P365) e peso aos 450 dias (P450), perímetro escrotal aos 450 dias (PE450), mérito genético total (MGT) e qual percentil o touro se encontra (TOP).

Na Tabela 1 encontram-se as DEPs avaliadas e com o número de animais estudados para cada uma delas. 
BUZZO, A.M.R. e MARTINEZ, A.C. Influência da diferença esperada na progênie no preço da dose do sêmen de touros da raça Nelore. PUBVET, Londrina, V. 8, N. 14, Ed. 263, Art. 1747, Julho, 2014.

TABELA 1: CARACTERÍSTICAS AVALIADAS E SEUS RESPECTIVOS NÚMEROS DE ANIMAIS

\begin{tabular}{lc}
\hline Característica & $\begin{array}{c}\text { Número de } \\
\text { animais }\end{array}$ \\
\hline PN & 90 \\
IPP & 113 \\
PG & 107 \\
PA & 88 \\
PAC & 107 \\
P120 & 113 \\
P365 & 113 \\
P450 & 113 \\
PE450 & 113 \\
MGT & 117 \\
TOP & 117 \\
\hline
\end{tabular}

Os prêmios usados na análise foram: $1^{\circ}$ Prêmio de Progênie, $2^{\circ}$ Prêmio de Progênie, 30 Prêmio de Progênie; 10 Prêmio de Bezerro, 30 Prêmio de Bezerro, Reservado Campeão Bezerro; 10 Prêmio Júnior Menor, $2^{\circ}$ Prêmio Júnior Menor, Campeão Júnior Menor e Reservado Campeão Júnior Menor; 10 Prêmio Júnior Maior, $2^{\circ}$ Prêmio Júnior Maior, $3^{\circ}$ Prêmio Júnior Maior, Campeão Júnior Maior e Reservado Campeão Júnior Maior; $1^{\circ}$ Prêmio de Touro Jovem, $2^{\circ}$ Prêmio de Touro Jovem, $3^{\circ}$ Prêmio de Touro Jovem, Campeão Touro Jovem e Reservado Campeão Touro Jovem; 10 Prêmio Sênior, $2^{\circ}$ Prêmio Sênior, $3^{\circ}$ Prêmio Sênior, Campeão Sênior e Reservado Campeão Sênior; 10 Prêmio de Progênie, $2^{\circ}$ Prêmio de Progênie, $3^{\circ}$ Prêmio de Progênie; Grande Campeão e reservado Grande Campeão, utilizando 86 animais em cada análise. E os prêmios de $2^{\circ}$ Prêmio de Bezerro e Campeão Bezerro com 85 animais em cada análise.

As características de DEPs e premiações foram correlacionadas com a 
BUZZO, A.M.R. e MARTINEZ, A.C. Influência da diferença esperada na progênie no preço da dose do sêmen de touros da raça Nelore. PUBVET, Londrina, V. 8, N. 14, Ed. 263, Art. 1747, Julho, 2014.

variável preço da dose de sêmen do reprodutor, as análises estatísticas foram realizadas com auxílio do PROC COR do programa SAS V8.0.

\section{RESULTADOS E DISCUSSÃO}

A média dos preços das doses foi de $R \$ 69,39$ reais, com um desvio padrão de 188,65 , sendo os valores mínimo e máximo $R \$ 8,00$ e $R \$ 1200,00$ respectivamente. Os resultados de correlação obtidos nesse trabalho estão mostrados nas Tabelas 2 e 3.

TABELA 2 - CORRELAÇÃO ENTRE O PREÇO DO SÊMEN E VARIÁVEIS PRODUTIVAS

\begin{tabular}{lc}
\hline Variáveis & Correlação \\
\hline PN & 0,176 \\
IPP & $-0,103$ \\
PG & 0,026 \\
PA & 0,077 \\
PAC & $-0,058$ \\
P120 & 0,072 \\
P365 & 0,012 \\
P450 & $-0,019$ \\
PE 450 & $-0,047$ \\
MGT & 0,018 \\
TOP & 0,006 \\
\hline
\end{tabular}


BUZZO, A.M.R. e MARTINEZ, A.C. Influência da diferença esperada na progênie no preço da dose do sêmen de touros da raça Nelore. PUBVET, Londrina, V. 8, N. 14, Ed. 263, Art. 1747, Julho, 2014.

TABELA 3 - CORRELAÇÃO ENTRE O PREÇO DO SÊMEN E VARIÁVEIS DE PREMIAÇÃO

\begin{tabular}{|c|c|}
\hline Variáveis & Correlação \\
\hline 10 prêmio progênie & 0,606 \\
\hline 20 premio progênie & 0,602 \\
\hline 30 premio progênie & 0,565 \\
\hline $1^{\circ}$ premio bezerro & $-0,055$ \\
\hline 20 premio bezerro & $-0,121$ \\
\hline 30 premio bezerro & $-0,034$ \\
\hline Campeão bezerro & $-0,068$ \\
\hline Reservado campeão bezerro & $-0,019$ \\
\hline $1^{0}$ premio Junior Menor & $-0,084$ \\
\hline 20 premio Junior Menor & $-0,069$ \\
\hline Campeão Junior Menor & $-0,054$ \\
\hline Reservado Campeão Junior Menor & $-0,088$ \\
\hline $1^{0}$ premio Junior Maior & $-0,057$ \\
\hline 20 premio Junior Maior & $-0,035$ \\
\hline 30 premio Junior Maior & $-0,049$ \\
\hline Campeão Junior Maior & 0,029 \\
\hline Reservado Campeão Junior Maior & $-0,089$ \\
\hline 10 Premio de Touro Jovem & $-0,071$ \\
\hline 20 Premio de Touro Jovem & $-0,084$ \\
\hline 30 Premio de Touro Jovem & $-0,049$ \\
\hline Campeão Touro Jovem & $-0,052$ \\
\hline Reservado Campeão Touro Jovem & $-0,091$ \\
\hline $1^{\circ}$ premio Sênior & $-0,056$ \\
\hline 20 premio Sênior & $-0,078$ \\
\hline 30 Premio Sênior & $-0,058$ \\
\hline Campeão Sênior & $-0,073$ \\
\hline Reservado Campeão Sênior & $-0,065$ \\
\hline Grande Campeão & 0,054 \\
\hline Reservado Grande Campeão & $-0,028$ \\
\hline
\end{tabular}


BUZZO, A.M.R. e MARTINEZ, A.C. Influência da diferença esperada na progênie no preço da dose do sêmen de touros da raça Nelore. PUBVET, Londrina, V. 8, N. 14, Ed. 263, Art. 1747, Julho, 2014.

As variáveis que tiveram altas correlações com o preço foram: $1^{0}$ prêmio de Progênie, com 60,6\%; $2^{\circ}$ prêmio de Progênie, com 60,2\% e 30 prêmio de Progênie, com $56,5 \%$, indicando que o número de prêmios que os filhos que um touro possui influencia no preço da dose do seu sêmen. Isso se dá pelo simples pensamento de que: se os filhos do touro em questão possuem várias premiações, é bem provável que seus novos filhos também venham a se diferenciar do rebanho e ganhar algum prêmio. Pensando desta forma, os produtores estão fazendo a seleção dos touros levando em consideração o fenótipo do doador, e deixando de lado o genótipo, avaliado através das DEPs, que é a característica que realmente importa quando se pensa em melhoramento genético de um plantel através da IA.

Outra característica que teve relação com o preço, porém não muito alta, foi o PN com um valor de $17,6 \%$. Essa é uma característica de seleção importante, pois o peso ao nascimento do animal já começa influenciando consideravelmente no seu desenvolvimento pré e pós-desmama de maneira negativa quando é muito baixo, ou dificultando partos quando se apresenta de maneira elevada. Desta forma, é possível observar que esta característica já vem sendo notada e usada pelos produtores e vem e influenciando o preço das doses de sêmen.

O P365 teve uma correlação muito baixa com o preço, sendo de $1,2 \%$, mas a mesma possui uma característica de herdabilidade média a alta, e considerando sua importância econômica por estar ligada ao desenvolvimento ponderal da progênie touro, era de se esperar uma maior influência dessa característica no preço final da dose de sêmen, porém isto não foi verificado no presente estudo. Baldi et al. (2012) concluíram que a previsão para ganho de peso deve ser utilizado em sistemas de produção animal, sendo uma característica de grande importância para o sistema de produção.

As demais variáveis, quando correlacionadas com o seu preço, apresentaram todas correlação inferior a $50 \%$, o que significa que essas características não influenciaram no preço final do produto

Os criadores vêm procurando empregar novas tecnologias para otimizar 
BUZZO, A.M.R. e MARTINEZ, A.C. Influência da diferença esperada na progênie no preço da dose do sêmen de touros da raça Nelore. PUBVET, Londrina, V. 8, N. 14, Ed. 263, Art. 1747, Julho, 2014.

os ganhos e eficiência dos rebanho, utilizando técnicas de melhoramento genético animal que tornam a pecuária de corte competitiva e atraente. A seleção, por ser uma das ferramentas do melhoramento genético animal, pode ser usada para modificar a constituição genética de uma população, o que ocorre devido à alteração das freqüências dos alelos que determinam a expressão das características de interesse, por meio de uma reprodução assistida com animais de desempenho superior comprovado (ZAMPAR, 2007), porém tem ocorrido que muitos produtores rurais, talvez até por desconhecimento, vêm escolhendo seus touros reprodutores levando em base o fenótipo.

Ainda, quando se dá maior importância ao fenótipo da progênie de um touro, esquece-se de que aquele indivíduo também está expressando a carga genética herdada da mãe, que talvez foi uma matriz com um potencial genético bem diferente das matrizes que o produtor dispõe. Ao se fazer uma seleção a partir do genótipo, o produtor pode escolher um touro que venha melhorar ou aprimorar as características das suas matrizes escolhendo as DEPs para cada característica.

$\mathrm{Na}$ literatura atual são escassos trabalhos que correlacionem o preço da dose de sêmen com essas características herdáveis do touro juntamente com os prêmios recebidos, até mesmo porque existem touros que são muito usados na IA que nunca foram pra uma exposição.

Madalena et al. (1995) encontraram que os prêmios em exposições e parentescos com touros famosos influenciaram no preço de sêmen da raça Nelore. Dias (1996), estudou a correlação do preço com os pesos (ao nascer, ao desmame e adulto) e com os prêmios e encontrou que pelo menos uma parte do mercado brasileiro de sêmen da raça Nelore já dá importância aos indicadores genéticos e também encontrou que o desempenho dos animais em exposição e sua ascendência são considerados pelo mercado no preço do sêmen. Vercesi Filho et al. (2007) ao estudarem os possíveis fatores que influenciam o preço do sêmen na Raça Gir, encontraram que as variáveis estudadas (pai do touro, status do touro, prova do touro, peso do animal e 
BUZZO, A.M.R. e MARTINEZ, A.C. Influência da diferença esperada na progênie no preço da dose do sêmen de touros da raça Nelore. PUBVET, Londrina, V. 8, N. 14, Ed. 263, Art. 1747, Julho, 2014.

produção de leite da mãe) influenciaram significativamente no preço do sêmen.

\section{CONCLUSÃO}

Com base nos resultados obtidos, pode ser observado que o preço da dose de sêmen não sofre influência das características genéticas que o touro vai passar para sua progênie, o que não era esperado que acontecesse, pois as DEPs servem para que o produtor avalie e escolha um touro que melhore geneticamente seu plantel.

Também foi possível observar que os prêmios de progênie influenciaram no preço final da dose de sêmen, mostrando que o que vem motivando a procura e compra de um sêmen em questão é o fato dos filhos desse touro ter prêmios. A partir disso conclui-se que, ainda nos dias de hoje, com todo o acesso à informação e à resultados de pesquisa, muitas pessoas ainda vêm dando preferência ao valor fenotípico dos touros doadores, e não ao valor do genótipo que sua progênie irá herdar.

\section{REFERÊNCIAS}

ABIEC - Associação Brasileira das Indústrias Exportadoras de Carne. Disponível em http://www.abiec.com.br/estatisticas relatorios.asp Acesso em 30/10/2008

ANUALPEC 2008. São Paulo: FNP,2008.

BARBOSA, V.; MAGNABOSCO, C.U.; DIAS, D.S.O.; FARIA, C.U.; MADUREIRA, A.P.; LÔBO, R.B.; BRITO, R.A.M. Inferência Bayesiana na Análise de Características de Crescimento Pósdesmame em Bovinos da Raça Nelore. In: REUNIÃO ANUAL DA SOCIEDADE BRASILEIRA DE ZOOTECNIA, 40, 2003, Santa Maria, Anais... Santa Maria: Sociedade Brasileira de Zootecnia, 2003. 5p.

BITTENCOURT, T.C.C.; ROCHA, J.C.M.C.; LÔBO, R.B.; BEZERRA, L.F.; Estimação de Componentes de (co)variâncias e Predição de DEP's para Características de Crescimento Pósdesmama de Bovinos da Raça Nelore, Usando Diferentes Modelos Estatísticos. Arquivo

Brasileiro de Medicina Veterinária e Zootecnia v.54, n.3, s.p., 2002.

BOLIGON, A.A.; RORATO, P.R.N.; ALBUQUERQUE, L.G. Correlações Genéticas Entre Medidas de Perímetro Escrotal e Características Produtivas e reprodutivas de Fêmeas da Raça Nelore.

Revista Brasileira de Zootecnia. V.36, n.3, p.565-571, 2007. 
BOLIGON, A.A.; VOZZI, P.A.; NOMELINI, J.; RORATO, P.R.N., BEZERRA, L.A.F.; LÔBO, R.B. Parâmetros Genéticos para Idade ao Primeiro Parto Estimados por Diferentes Modelos para Rebanhos da Raça Nelore. Ciência Rural, v.38, n.2, p.432-436, 2008a.

BOLIGON, A.A.; ALBUQUERQUE, L.V.; RORATO, P.R.N.; Associações Genéticas entre Pesos e Características Reprodutivas em Rebanhos da Raça Nelore. Revista Brasileira de Zootecnia, v.37, n.4, p596-601, 2008b.

BORJAS, A.R.; ELZO, M.A., LÔBO, R.B.; BEZERRA, L.A.F. Efecto de La Selección de Toros Nelore Jóvenes para Perímetro Escrotal Sobre Características de Crescimento de sus Progênies. Livestock Research for Rural Development, v.15, n.10, s.p. 2003.

CATER, A.H. Effectiveness of Growth Performance in Cattle. Proceedings of New Zealand Society of Animal Production, v.31.p.151-163.1971.

CNA - Confederação da Agricultura e Pecuária do Brasil. Disponível em: www.cna.org.br

COSTA, L.C.O Melhor Nelore do Mundo = The Best Nelore in the World. s.ed. São Paulo: Columbus, 1989. 73p

CYRILLO, J.N.S.G.; RAZOOK, A.G.; FIGUEIREDO, L.A.; NETO, L.M.B.; RUGGIERI, A.C.; TONHATI, H. Efeitos da Seleção para Pesos Pós-desmame Sobre Medidas Corporais e Perímetro Escrotal de Machos Nelore de Sertãozinho. Revista Brasileira de Zootecnia, n.29, v.2, p.403-412, 2000.

DIAS, F.M.G.N. Fatores que Influenciam o Preço de Sêmen de Nelore. In: SIMPÓSIO NACIONAL DE MELHORAMENTO ANIMAL, 1, 1996, Ribeirão Preto. Proccedings... Ribeirão Preto: Sociedade Brasileira de Melhoramento Animal, 1996, p.209-212.

DIAS, L.T.; FARO, L.E.; ALBUQUERQUE, L.G.; Estimativas de Herdabilidade para Idade ao Primeiro Parto de Novilhas da Raça Nelore. Revista Brasileira de Zootecnia, v.33, n.1, p.97102, 2004.

DIAS, L.T.; ALBUQUERQUE, L.G.; TONHATI, H.; TEIXEIRA, R.A. Estimação de Parâmetros Genéticos para Peso em Diferentes Idades para Animais da Raça Tabapuã. Revista Brasileira de Zootecnia, v.34, n.6, p.1914-1919, 2005.

ELER, J.P.; VAN VLECK, L.D.; FERRAZ, J.B.S.; LÔBO, R.S. Estimation of Variances Due to Direct and Maternal Effects for Growth Traits of Nelore Cattle. Journal of Animal Science, v.73, p.3253-3258, 1995

ELER, J.P., FERRAZ, J.B.S., SILVA, P.R. Estimação Simultânea de Parâmetros de Importância Econômica na Raça Nelore, com a Utilização de Modelos Animais. In: REUNIÃO ANUAL DA SOCIEDADE BRASILEIRA DE ZOOTECNIA, 33, 1996, Fortaleza, CE. Anais... Fortaleza: Sociedade Brasileira de Zootecnia, p.99-101, 1996.

FARIA, C.U.; MAGNABOSCO, C.U.; ALBUQUERQUE, L.G.; REYES, A. de los, BEZERRA, L.A.F.; LÔBO, R.B. Análise Genética de Escores de Avaliação Visual de Bovinos com Modelos Bayesianos de Limiar e Linear. Pesquisa Agropecuária Brasileira, v.43, n.7, p.835-841, 2008.

FREITAS, A.R.; LOIBEL, S.M.C.; ANDRADE, M.G.; VAL, J.B.R. do. O Crescimento Populacional do Rebanho Bovino Brasileiro. In: REUNIÃO ANUAL DA SOCIEDADE BRASILEIRA DE ZOOTECNIA, 40, 2003, Santa Maria. Anais... Santa Maria: Sociedade Brasileira de Zootecnia, 2003. 7p. 
GARDNER, E.J.; SIMMONS, M.J.; SNUSTAD, D.P. Princípios de Genética. $4^{a}$ Ed. México, D.F.: Limusa Wiley, 2000. p23.

GARNERO, A. V.; FERNANDES, M.B.; FIGUEIREDO, L.F.C.; LÔBO, R.B. Influência da Incorporação de Dados de Progênies na Classificação de Touros da Raça Nelore. Revista Brasileira de Zootecnia, v.31, n.2, p.918-923, 2002 (suplemento).

GRESSLER, S.L.; BERGMANN, J.A.G.; PEREIRA, C.S.; PENNA, V.M.; PEREIRA, J.C.C.; GRESSLER, M.G.M. Estudos das Associações Genéticas entre Perímetro Escrotal e Características Reprodutivas de Fêmeas Nelore. Revista Brasileira de Zootecnia, v.29, n.2, p.427-437, 2000.

GRESSLER, M.G.M.; PEREIRA, J.C.C.; BERGMANN, J.A.G.; ANDRADE, V.J.; PAULINO, M.F.; GRESSLER, S.L. Aspectos Genéticos do Peso a Desmama e de Algumas Características Reprodutivas de Fêmea Nelore. Arquivo Brasileiro de Medicina Veterinária e Zootecnia, v57, n4, p.533-538, 2005.

GRIFFITHS, A.J.F.; GRLBART, W.M.; MILLER, J.H.; LEWONTIN, R.C. Genética Moderna. S. Ed. Rio de Janeiro: Guanabara Koogan, 2001. P13, 523.

GUNSKI, R.J.; GARNERO, A.V.; BORJAS, A.R.; BEZERRA, L.A.F.; LÔBO, R.B.; Estimativas de Parâmetros Genéticos para Características Incluídas em Critérios de Seleção em gado Nelore. Ciência Rural, Santa Maria, v.31, n.4, p.603-607, 2001a.

GUNSKI, R.J.; GARNERO, A.V.; BEZERRA, L.A.F.; CORRADO, M.C.; LÔBO, R.B.; Idade ao Primeiro Parto, Período de Gestação e Peso ao Nascimento na Raça Nelore. Ciência Agronômica, v.32, n.1/2, p.46-52, 2001b.

IEL, CNA E SEBRAE. Estudo Sobre a Eficiência Econômica e Competitividade da Cadeia Agroindustrial da Pecuária de Corte no Brasil. Brasília, D.F. : IEL, 2000.

JOSAHKIAN, L.A. Programa de Melhoramento Genético das Raças Zebuínas. In: SIMPÓSIO NACIONAL DE MELHORAMENTO ANIMAL, 3, 2000, Belo Horizonte. Anais... Belo Horizonte: Sociedade Brasileira de Melhoramento Animal, 2000. p. 76-93.

KRIESE, L.A.; BERTRAND, J.K.; BENYSHEK, L.L. Age Adjustment Factors, Heritabilities and Genetic Correlations for Scrotal Circumference and Related Growth Traits in Hereford and Brangus Bulls. Journal of Animal Science, v.69, p.478-489, 1991.

LIRA, T.; ROSA, E.M.; GARNERO, A.V. Parâmetros Genéticos de Características Produtivas e Reprodutivas em Zebuínos de Corte (Revisão). Ciência Animal Brasileira. v.9, n.1, p.1-22, 2008.

LÔBO, R.B.; BEZERRA, L.A.F.; OLIVEIRA, H.N.; MAGNAOSCO, C.de U.; ZAMBIANCHI, A.R.;BERGMANN, J.A.G; SAINZ, R.D. Avaliação Genética de Animais Jovens, Touros e Matrizes. Ribeirão Preto, FMRP - USP - GEMAC - Departamento de Genética. Riber Gráfica e Editora, 94p., 2003.

LÔBO, R.B.; BEZERRA, L.A.F.; FARIA, C.de U.; MAGNABOSCO, C. de U.; ALBUQUERQUE, L.G.; BERGMANN, J.A.G.; SAINZ, R.D.; OLIVEIRA, H.N. Avaliação Genética de Touros e Matrizes da Raça Nelore: Sumário 2008. Ribeirão Preto, ANCP. 124p. 2008. 
LOPES, J.S.; RORATO, P.R.N.; WEBER, T.; BOLIGON, A.A.; COMIN, J.G.; DORNELLES, M.A. Efeito da Interação Genótipo x Ambiente Sobre o Peso ao Nascimento, aos 205 e aos 550 dias de Idade de Bovinos da Raça Nelore na Região Sul do Brasil. Revista Brasileira de Zootecnia, v.37, n1, p54-60, 2008.

MADALENA, F.E.; VERNEQUE, R.S.; TEODORO, R.L. Fatores que Influenciam o Preço do Sêmen Importado. Revista Brasileira de Genética, v.8, p.377-384, 1995.

MARTIN, L.C.; BRINKS; J.S.; BOURDON, R.M.; CUNDIFF, L.V. Genetic Effects on Beef Heifer Puberty and Subsequent Reproduction. Journal of Animal Science, v.70, p.4006-4017, 1992.

MUSTEFAGA, P.S. Pecuária: Brasil Mantém Liderança no Mercado Mundial da Carne. CNA, n204. 2004. Disponível em http://www.cna.org.br/site/noticia.php?ag=0\&n=4218 Acesso em 10 set. 2008.

NIETO, L.M.; SILVA, L.O.C.; MARTINS, E.N.; ROSA, A.N.; TORRES JUNIOR, R.A.de A. Correlación Genética entre Precocidad Sexual, Características de Desempeño y Reproductivas em La Raza Nelore. Livestock Research for Rural Development, v.19, n.11, 7p., 2007.

PANETO, J.C.C.; FIGUEIREDO, L.F.C.; CARDOSO, M.C.P.; BEZERRA, L.A.F.; LÔBO. R.B. Retorno Econômico das Avaliações Genéticas. In: SIMPÓSIO NACIONAL DE MELHORAMENTO ANIMAL, 3, 2000, Belo Horizonte. Anais... Belo Horizonte: Sociedade Brasileira de Melhoramento Animal, 2000. P.356-358.

PEREIRA, E.; ELER, J.P.; FERRAZ, J.B.S.; Correlação Genética entre Perímetro Escrotal e Algumas Características Reprodutivas na Raça Nelore. Revista Brasileira de Zootecnia, v.29, n.6, p.1676-1683, 2000.

PEREIRA, E., ELER, J.P., FERRAZ, J.B.S. Análise Genética de Algumas Características Reprodutivas e suas relações com o desempenho Ponderal na raça Nelore. Arquivo Brasileiro de Medicina Veterinária e Zootecnia. v.53, n.6, p.720-727, 2001

PEREIRA, E.; ELER, J.P.; FERRAZ, J.B.S.; Análise Genética de Características Reprodutivas na Raça Nelore. Pesquisa Agropecuária Brasileira, v.37, n.5, p.703-708, 2002.

PEREIRA, J.C.C.; RIBEIRO, S.H.A.; SILVA, M.A.; BERGMANN, J.A.G.; COSTA, M.D. Análise Genética de Características Ponderais e Reprodutivas de Fêmeas Bovinas Tabapuã. Arquivo Brasileiro de Medicina Veterinária e Zootecnia. v.57, supl. 2, p. 231-236, 2005.

PINEDA, N.R. Influencia do Zebu na Produção de Carne no Brasil. In: SIMPÓSIO NACIONAL DE MELHORAMENTO ANIMAL, 3, 2000, Belo Horizonte. Anais... Belo Horizonte: Sociedade Brasileira de Melhoramento Animal, 2000. p. 130-149. Disponível em: http://www.sbmaonline.org.br/anais/iii/palestras/iiip17.pdf

SHIOTSUKI, L.; MARCONDES, C.R.; NOMELINI, J.; CARVALHO, S.C.; NASCIMENTO, T.R.; LÔBO, R.B. Criação e Impacto do Uso de Touros Geneticamente Superiores da Raça Nelore Padrão. In: SIMPÓSIO DA SOCIEDADE BRASILEIRA DE MELHORAMENTO ANIMAL, 5, 2004, Pirassununga. Anais... Pirassununga: Sociedade Brasileira de Melhoramento Animal, 2004. 3p.

SNUSTAD, D.P.; SIMMONS, M.J.; Fundamentos de genética. 2.ed. Rio de Janeiro: Guanabara Koogan, 2001. p50-51, 71, 81. 
VERCESI FILHO, A.E.; EL FARO, L. ; PAZ, C.C.P.; CARDOSO, V.L.; SILVA, D.A.L.; JUNQUEIRA, F.S. Fatores que Influenciam o Preço do Sêmen de Touros da Raça Gir Leiteiro. In: REUNIÃO ANUAL DA SOCIEDADE BRASILEIRA DE ZOOTECNIA, 44, 2007, Jaboticabal. Anais... Jaboticabal: Sociedade Brasileira de Zootecnia, 2007. 3p.

ZAMPAR, A. Comparação de estimativas de diferenças esperadas na progênie por três metodologias em touros da raça Nelore. 65p. Dissertação (Mestrado em Zootecnia) -

Faculdade de Zootecnia e Engenharia de Alimentos, Universidade de São Paulo, Pirassununga, 2007. 